\title{
Banco Mundial e educação no Brasil: a consolidação da lógica privatista e mercantilizada do ensino superior
}

\author{
World Bank and education in Brazil: the consolidation of the privatized and commodified \\ logic of higher education
}

\author{
Ednéia Alves de Oliveira* \\ Jéssica Adriele Tomaz Pereira**
}

\begin{abstract}
Resumo: Este artigo é parte de uma pesquisa bibliográfica e documental sobre a influência do Banco Mundial (BM) na política educacional brasileira. Objetiva analisar os últimos relatórios publicados pelo BM para identificar as diretrizes propostas para a educação nos países da periferia capitalista, em especial o Brasil. De acordo com os nossos estudos identificamos uma tendência na adequação da política educacional brasileira proposta por esta organização internacional, em que se destaca a tecnificação, mercantilização e privatização do ensino superior, atendendo aos interesses do capital internacional e financeiro.
\end{abstract}

Palavras-chave: Banco Mundial, política educacional, privatização, mercantilização, Brasil

\begin{abstract}
This article is part of a bibliographical and documentary research about the influence of the World Bank (WB) on Brazilian educational policy. It aims to analyze the latest reports published by the $B M$ to identify the proposed guidelines for education in capitalist peripheral countries, especially Brazil. According to our studies, we can identify a trend in the adequacy of the brazilian educational policy proposed by this international organization, which highlights the technification, commodification and privatization of higher education in the interests of international and financial capital.
\end{abstract}

Keywords: World Bank, educational policy, privatization, commodification, Brazil.

\footnotetext{
* Assistente social, doutora em Serviço Social pela Universidade do Estado do Rio de Janeiro (Uerj), professora do Programa de Pós-Graduação da Universidade Federal de Juiz de Fora (UFJF), e da graduação, lotada no Departamento de Política e Ação do Serviço Social. E-mail: oliveiraedneia21@yahoo.com.br

** Assistente Social, mestra em Serviço Social pela Universidade Federal de Juiz de Fora (UFJF). E-mail: jessicatomaz7@yahoo.com.br
} 


\section{Introdução}

Este artigo objetiva analisar os últimos relatórios do Banco Mundial e sua influência nas diretrizes da política educacional para os países da periferia, em especial destaque para a brasileira. A metodologia utilizada consistiu em revisão bibliográfica e pesquisa documental através dos relatórios publicados pelo Banco Mundial nos últimos anos. Nosso entendimento é que esses relatórios reafirmam a tendência de uma educação técnica e mercantilizada, sobretudo no ensino superior, que prima pelo favorecimento de uma formação privatista, a serviço da lógica do endividamento e, consequentemente, privilegia o capital financeiro. Nesse sentido, a educação superior no Brasil tem convivido com a ampliação de cursos à distância e também com financiamento via bolsas e créditos estudantis para o setor privado, mercantilizando e promovendo uma formação de baixa qualidade, o que nos possibilita constatar nossa hipótese inicial.

Para elucidar nossas análises realizaremos uma breve retomada histórica do início dessa influência, datada do período do regime civil-militar no Brasil com os acordos MEC/USAID. A influência nas reformas educacionais em todos os níveis da educação, junto a uma forte repressão nas universidades, demonstrava a total consonância das políticas norteamericanas para a educação dos países periféricos. Tais direcionamentos indicavam o incremento das privatizações e a crescente mercantilização da educação com enfoque no ensino superior ao sugerir em vários relatórios que as universidades públicas deveriam cobrar taxas de matrícula e mensalidades e que fosse implantado um sistema de financiamento estudantil para os que não pudessem pagar.

A partir de meados dos anos 2000 o país vivenciou o processo de expansão das universidades públicas e privadas em proporções ainda maiores do que aquelas registradas na ditadura civil-militar, originando os grandes conglomerados de ensino superior privado e a consolidação, nas terras além-mar, de um dos maiores grupos educacionais: o grupo Króton. Salientamos que, por mais que a expansão tenha possibilitado a inserção de um contingente maior de estudantes na universidade pública, pela via do Reuni, o foco principal da expansão do ensino estava nos interesses mercadológicos das empresas privadas de educação que lucraram e continuam a lucrar com programas de financiamento como o Fies ou de concessão de bolsas como o Prouni. 
Nesse sentido, a educação superior como educação terciária, conforme aponta o Banco Mundial, é mais uma estratégia de vender e flexibilizar os conteúdos de forma tecnicista e acrítica, criando uma massa atomizada capaz de reproduzir a lógica do capital em seus mais diversos aspectos, seja pela concordância com o modelo imposto, seja pela baixa qualificação dessa força de trabalho e a permanência de salários baixos e sem acesso a benefícios trabalhistas, ao reforçar a inserção subalterna e periférica do Brasil na divisão internacional do trabalho. Não por acaso, os investimentos em ciência e tecnologia vem sofrendo cortes consideráveis desde 2013. Para 2019, com o novo governo, a tendência é de redução ainda mais aguda, devido aos interesses mercadológicos e predatórios que ora ocupam o poder. Destacamos ainda a prioridade para áreas que possam obter recursos privados para financiamento de pesquisas e projetos, o que vem a subordinar o ensino superior a uma dinâmica privatista como asseveram as cartilhas do Banco Mundial.

\section{Banco Mundial e a educação brasileira: uma análise dos relatórios e os impactos para a política educacional no brasil}

A educação brasileira, assim como nos demais países, foi concebida para atender aos interesses do capital. Inicialmente como formação da força de trabalho qualificada para o mercado de trabalho ou ainda para reprodução ideológica da burguesia e, posteriormente, como mecanismo que preserva os elementos supracitados, mas também como mercadoria duplamente qualificada, atendendo aos interesses do capital produtivo e também financeiro. Marx (2012), ao escrever a Crítica ao Programa de Gotha, nos alertava para o fato de que o Estado, e aqui nos referimos ao Estado burguês, não poderia ser responsável pela educação do povo. A preocupação do autor consistia no fato de que o Estado não é uma instituição neutra, mas permeada por interesses que são antagônicos aos da classe trabalhadora. Portanto, só pode desenvolver uma educação que esteja afinada com os interesses da classe dominante. Essa assertiva pode ser comprovada pela própria trajetória histórica que a educação percorreu nos diversos países capitalistas.

No caso do Brasil, objeto da nossa análise, a educação brasileira sempre foi direcionada para atender os interesses do país e seu processo de industrialização. Já nos governos que antecederam a ditadura percebemos uma segregação educacional entre a formação da classe trabalhadora e da classe dominante. Tal segregação permitiu a 
constituição de um mercado de trabalho informal amplo, disparidades salariais e regionais, uma nítida separação entre trabalho manual e intelectual e a ausência de políticas trabalhistas que permitissem a sobrevivência do trabalhador enquanto fora do mercado de trabalho (OLIVEIRA, 2016). Outro fator que merece destaque é a dicotomia entre o ensino superior e o ensino fundamental, aprofundando uma sobrevalorização do ensino superior em detrimento do ensino fundamental. Não por acaso, o país conviveu com altos índices de analfabetismo que, em determinados momentos chegaram a atingir em torno de mais da metade da população.

Com o golpe que levou ao poder a ditadura civil-militar, essa tendência se agravou, pois, a incorporação de preceitos mercadológicos permitiu que a educação fosse constituída como uma mercadoria que atendesse tanto aos interesses do capital produtivo quanto financeiro. A parceria firmada entre Brasil e Estados Unidos da América (EUA), através dos acordos entre o Ministério da Educação e Cultura e United State Agency for International Development - MEC-USAID, objetivou realizar uma profunda reforma no ensino brasileiro baseada na implantação do modelo norte americano nas universidades brasileiras. Para a consolidação desse acordo, o Brasil receberia assistência técnica e cooperação financeira dos EUA para aprimorar a reforma educacional em curso, pois a educação foi entendida como um instrumento importante de reprodução ideológica da desigualdade social e também como uma mercadoria que pudesse gerar lucros ao mercado.

Essa reforma não apenas adequou a política educacional aos interesses do capital internacional como também diminuiu os gastos públicos e incentivou investimentos em setores privados, prioritários para o capital internacional. Para Netto (2005, p. 62) "transformou, pela primeira vez na história brasileira, o ensino superior num setor para investimentos capitalistas privados extremamente rentáveis - a educação superior, sob a autocracia burguesa, transformou-se num "grande negócio". Ou seja, foi durante a ditadura civil-militar que ocorreu o processo de expansão das universidades privadas, cursinhos prévestibulares e ensino fundamental e médio, garantindo o ingresso de corporações internacionais no controle do ensino como exemplifica o caso do grupo Pitágoras ${ }^{1}$.

\footnotetext{
${ }^{1}$ O grupo Pitágoras iniciou suas atividades na década de 1960 como cursinho pré-vestibular e hoje oferece do ensino fundamental ao médio, sendo uma das maiores redes de ensino privado no Brasil. Em 1979, começaram as operações internacionais, com a abertura de colégios Pitágoras em diversos países do mundo em parceria com grandes empresas. A partir de 2007, o Pitágoras passou a fazer parte do grupo Króton Educacional, representaNDO atualmente uma das maiores organizações do setor educacional a nível mundial (TOMÁZ, 2019).
} 
Data desse período, a primeira das reformas oficializadas. A Lei oㅡ 5.540/68 (Lei da Reforma Universitária), possibilitou a criação de cursos profissionais de curta duração, bem como a exigência de que os cursos superiores atendessem às peculiaridades do mercado de trabalho, sujeitando a formação às demandas do mesmo. Essa lei, portanto, corroborou com a proposta de cursos adequados à realidade socioeconômica já preconizada pela Lei de Diretrizes e Bases da Educação (LDB) de 1961.

\begin{abstract}
Com a reforma universitária (departamentalização, regime de créditos, instituição do ciclo básico, vestibular unificado, fragmentação do grau acadêmico de graduação, institucionalização da pós-graduação) não só propiciaram ao Estado uma enorme economia de recursos como, sobretudo, instituíram mecanismos de exclusão no interior do próprio sistema universitário (NETTO, 2005, p.62).
\end{abstract}

O mercado de trabalho buscou alternativas para qualificar a força de trabalho nas universidades públicas por meio de mecanismos, que segundo Netto (2005, p. 66), foram funcionais ao regime autocrático e ao capital internacional, ao criar uma "universidade neutralizada, esvaziada, reprodutiva e asséptica". Esta tem sido a perspectiva balizadora da política educacional desde a ditadura e, que, atualmente, vem sendo posta pelas agências multilaterais, como Banco Mundial (BM) e Fundo Monetário Internacional (FMI), em total consonância com o movimento de financeirização da economia e de mercantilização das políticas sociais de forma geral.

Com o processo de redemocratização, essa tendência não se alterou. Pelo contrário, o processo de mercantilização da educação, foi alvo de políticas contundentes no governo de FHC, em que se destaca a reformulação da Lei de Diretrizes e Bases da Educação Nacional (LDBEN) em 1996, possibilitando ao setor privado a sua expansão e consolidando o ensino à distância como modalidade a ser utilizada em todos os níveis de ensino. Dessa forma reconheceu-se a educação, sobretudo a superior, como um bem de serviço comercializável, isto é, como um objeto de lucro ou acumulação, uma mercadoria ou a educação-mercadoria, de interesse dos empresários da educação (FERREIRA, PEREIRA e SOUZA, 2017).

Ainda de acordo com as autoras supracitadas, podemos observar a mudança de configuração do ensino superior brasileiro, com um crescimento expressivo do Ensino à Distância (EaD), principalmente a partir de 2003. Os dados demonstram que "se os cursos presenciais, entre 2003 e 2015 tiveram um crescimento de 70,65\%, aqueles ofertados à distância obtiveram um crescimento, no mesmo período, da ordem de 2.692,47\%" (FERREIRA, PEREIRA e SOUZA, 2017: p.193). Os dados comprovam que a matrícula de ensino superior tem 
sido majoritariamente na modalidade à distância, ofertadas na sua maioria por instituições privadas de ensino. A opção por essa modalidade favorece a precarização da qualidade do ensino e do trabalho docente, ao mesmo tempo que propicia ganhos maiores às empresas educacionais, gerando um mercado de bolsas e financiamentos públicos sob a justificativa de democratização do ensino superior.

A expansão da formação EaD foi proporcionado pela oferta do setor público, com a criação em 2005 da Universidade Aberta do Brasil (UAB) no governo Lula. A ênfase na formação de professores (licenciaturas) promoveu uma multiplicação de empresas educacionais para atender a esta demanda. Esse processo de mercantilização da educação, de acordo com Neves (2004, p.9) se deu "sob a direção técnica e ético-política dos organismos internacionais - em especial do Banco Mundial e do Fundo Monetário Internacional (FMI)" com suas principais alterações no início das últimas décadas do século $X X$ dentro de um processo de mundialização da educação (MELO, 2005).

O processo de expansão do ensino superior a partir de 2004, pode ser evidenciado pela criação do Programa Universidade para Todos (PROUNI). Este programa objetiva ofertar bolsas de estudos, integral e parcial, para estudantes com baixos ou poucos recursos socioeconômicos em instituições privadas de educação superior, através de parcerias públicoprivadas (PPP) e da garantia de "isenção fiscal para o setor privado em troca de "vagas públicas" nas IES privadas" (LIMA,2011, p.91).

Neste mesmo período foi criada a Lei de Inovação Tecnológica (Lei no 10.973/2004), que viabilizava as parcerias entre as IES públicas e as empresas privadas, abrindo as portas das universidades públicas para os interesses do capital através da criação de fundações para financiar as pesquisas desenvolvidas mediante os interesses do mercado. Essas parcerias possibilitam a terceirização do setor público para que empresas possam desenvolver pesquisas em Instituição Científica, Tecnológica e de Inovação (IC\&T). 
Outro movimento na direção da mercantilização do conhecimento, segundo Lima (2017), data de 2007 com as alterações na Lei de Incentivo Fiscal à Pesquisa (Lei n¹1.487/2007), consagrando uma subordinação da pesquisa e dos programas de pósgraduação à concepção mercadológica da educação e do conhecimento. Isso se deu através do direcionamento de investimentos a pesquisas que estejam diretamente relacionadas aos interesses do mercado, ao restringir o acesso e a distribuição de bolsas a cursos e pesquisas que não comprovem sua relação direta com interesses do capital.

Outro programa a ser destacado é o Fundo de Financiamento Estudantil (FIES), sucessor do Crédito Educativo, o CREDUC, criado em 1976 pelo regime civil-militar. Renomeado no governo FHC em 1999, tornou-se uma fonte de crédito para estudantes de universidades privadas. Em 2007, o FIES foi alterado pela Lei no 11.552, ampliando sua cobertura em até $100 \%$ dos encargos educacionais e expandiu a possibilidade de financiamento de cursos de mestrado e doutorado, além de outras determinações como: tempo limite, demandas exigidas as instituições conveniadas, percentuais a serem recebidos e outras providências.

Com o PROUNI e as demais leis criadas, o governo brasileiro permitiu que empresas privadas pudessem se aproveitar da estrutura física das universidades públicas para desenvolver as pesquisas que atendessem melhor aos seus interesses. As vantagens usufruídas variam desde os lucros adquiridos pela propriedade intelectual, voltada para a aplicação em setores chaves da economia, quanto nos grandes conglomerados educacionais que se formaram por meio da expansão das universidades privadas estimulada pelas bolsas de estudos do PROUNI e o crédito do FIES. Nessa perspectiva os grandes monopólios de ensino privado de educação superior no Brasil foram se consolidando nos últimos anos, caso do Grupo Króton, considerada a maior empresa privada de educação superior do mundo.

Para contrarrestar a tendência privatista e mercadológica do ensino superior, o governo federal criou, em 2007, o Programa de Apoio a Planos de Reestruturação e Expansão das Universidades Federais (Reuni), criado pelo Decreto № 6.096/2007. O objetivo do Reuni era, além de maior democratização do ensino superior: 1) aumentar o número de estudantes de graduação nas universidades federais; 2 ) aumentar o número de alunos por professor na graduação; 3) diversificar as modalidades dos cursos de graduação através da flexibilização dos currículos, da educação à distância, da criação dos cursos de curta duração e dos ciclos (básico e profissional); 4) incentivar a criação de um novo sistema de títulos; 5) elevar a taxa 
de conclusão dos cursos de graduação para $90 \%$ e, 6) estimular a mobilidade estudantil entre as instituições de ensino, no prazo de cinco anos (LIMA, 2011).

Contudo, as expectativas não foram consolidadas. De acordo com a Sinopse Estatística da Educação Superior do INEP (2016), o processo de expansão do Reuni foi inferior se comparado à expansão do ensino nas instituições privadas. Estas apresentaram um quantitativo de matrículas em torno de $75 \%$ enquanto o setor público respondia a apenas $24 \%$ desse quantitativo. Os dados demonstram que a perspectiva democratizante da educação superior esbarrava nos interesses econômicos e políticos do capital e a necessidade de obter lucros com a mercadoria educação.

\section{A mercantilização da educação e as "orientações" do Banco Mundial}

A crescente mercantilização e privatização da educação brasileira com programas de financiamento e bolsas de estudos ao ensino superior privado evidencia que "é no movimento de transferência, para a esfera mercantil, de atividades que até então eram estritamente regulamentadas e administradas pelo Estado, que o movimento de mundialização do capital encontra as suas maiores oportunidades de investir" (CHESNAIS, 1996, p.186). Nesse contexto, as políticas a serem estabelecidas serão direcionadas com o objetivo de atender a tais interesses através das diretrizes e sugestões das agências multilaterais, como o BM, que irão influenciar na elaboração e implantação de políticas sociais em todo o globo, com maior ênfase nos países periféricos.

De acordo com Martins (2015, p.103), “as condicionalidades implícitas nos empréstimos das instituições financeiras internacionais reproduzem o caráter de dependência, da subalternidade na divisão internacional do trabalho e na estrutura do sistema-mundo (centro, periferia e semi-periferia)". Estas condicionalidades figuram entre as principais estratégias que os países de capitalismo central encontram para manter a subordinação e a condição de dependência dos países periféricos, pois para receber os empréstimos e investimentos internacionais se faz necessário adequar as políticas e condições de trabalho a tais exigências. Para evidenciar tais influências nos referenciamos aos relatórios elaborados pelo Banco Mundial e que funcionam como uma espécie de cartilha a ser implementada nos países da periferia. Os pressupostos defendidos nesses relatórios 
demonstram a perfeita consonância com os interesses do capital internacional financeiro, denotando a estreita relação entre o Estado brasileiro e as exigências do capital internacional.

A título de demonstrar como essa relação ocupa posição de longa data destacamos o relatório de 1986, sob o título: "El financiamiento de la educación en los países en desarrollo: opciones de política". Esse relatório já apontava algumas sugestões a serem introduzidas gradualmente na política educacional brasileira com destaque para três elementos principais: i) a recuperação dos gastos públicos com educação superior e reassinatura do gasto público em educação a favor dos níveis que ofereçam maiores benefícios sociais; ii) a criação de um mercado de empréstimos para a educação, conjuntamente com o outorgamento de bolsas seletivas, especialmente no nível superior; e iii) a descentralização da administração da educação pública e fomento da expansão das escolas privadas e das financiadas pelas comunidades.

No relatório de 1996 intitulado “Prioridades y estratégias para la educación: examen del Banco Mundial" as diretrizes já sinalizam para uma perspectiva de reforçar o estímulo ao endividamento da população em benefício da esfera financeira. Notamos que esses relatórios foram seguidos pelos governos brasileiros de forma a consagrar uma política educacional mercadológica, discriminatória e condizente com os ditames do capital financeiro. Nos fragmentos abaixo está detalhado quais são as prerrogativas que os governos da periferia devem considerar na implementação de uma política para a educação nacional.

\begin{abstract}
A cobrança de taxas em todo o ensino público superior, combinado com planos de empréstimo, impostos e outros tipos de planos, para que os alunos que não possam pagar as taxas com seus rendimentos ou os dos pais podem adiar o pagamento até que tenham rendimentos próprios. Este sistema estaria acompanhado de um plano de bolsas dirigidas especificamente para superar a resistência dos pobres para acumular dívidas contra os rendimentos futuros que ainda não estão seguros de receber (Banco Mundial, 1996, p.116) ${ }^{2}$
\end{abstract}

A recente reformulação do FIES, implementado em 2018, materializa essas tendências ao dividir o programa em três diferentes modalidades, sendo a primeira a juros zero, a segunda com juros até 3\% mais correções monetárias, ambos geridos pelos bancos de

\footnotetext{
${ }^{2}$ Tradução realizada pelas autoras de acordo com o fragmento: “Cobro de derechos en toda la enseñanza pública superior, combinado con planes de préstamo, tributarios y de otra índole, a fin de que los alumnos que no pueden pagar los derechos con sus ingresos o los de sus padres puedan aplazar el pago hasta que tengan ingresos propios. Este sistema estaría acompañado de un plan de becas dirigidas específicamente a vencer la resistencia de los pobres a acumular deudas contra ingresos futuros que aún no están seguros de percibir" (BANCO MUNDIAL, 1996, p.116).
} 
participação mista com o governo. E a terceira destinada aos estudantes com renda per capita mensal familiar de até cinco salários mínimos. Esta modalidade abre a possibilidade de que os financiamentos sejam realizados com recursos de bancos privados participantes. Ou seja, garante maiores possibilidades de acúmulo por meio das instituições financeiras privadas. Essa política permite às instituições financeiras lucrarem e gerirem os recursos em conjunto com os grandes conglomerados educacionais em um nítido processo de financeirização da educação no contexto de mundialização do capital e da educação ${ }^{3}$.

O relatório de 2002 "Construir sociedades de conocimiento: nuevos desafíos para la educación terciaria", aprofunda as diretrizes da intensificação da mercantilização ao operar no "deslocamento da concepção de "educação superior" para "educação terciária" 4 . Baseado na ideia de "sociedade do conhecimento", o relatório estimula medidas que favoreçam essa formação, desde que,

[...] incrementem a diversificação institucional (aumento do número de instituições não universitárias e privadas) para ampliar a cobertura sobre uma base financeira viável e para estabelecer um marco de formação contínua com múltiplos pontos de acesso e grande variedade de itinerários formativos (Banco Mundial, 2002, p. 27) 5 .

Lima (2011) chama a atenção para esse processo ao longo da década de 1990 e que se consolida nos anos subsequentes, ao demonstrar como foi sendo implantado e racionalizado todo e qualquer curso, público ou privado, considerado de nível "terciário" 6 , seja através da emissão de diplomas, certificados ou atestados de aproveitamento, que alteram o formato e exigência de formação anteriormente construído.

Nas décadas passadas, muitos países experimentaram uma extraordinária
diversificação em seus setores de educação terciária. A aparição de diversas
instituições novas paralelas às universidades tradicionais - institutos técnicos para
estudos de curta duração, colégios comunitários, politécnicos, centros de educação
terciária popular com programas bienais, centros de ensino à distância e
universidades abertas - criaram novas oportunidades para satisfazer a demanda
social crescente. Na América Latina, Ásia e, mais recentemente, na Europa Oriental

${ }^{3}$ O FIES atualmente possui um total de 2,7 milhões de contratos e um elevado número de 453 mil estudantes inadimplentes, todos sem chances de negociar com a Caixa Econômica Federal. No momento, este índice de devedores equivale a um débito total de $\mathrm{R} \$ 10$ bilhões com o fundo. (BRASIL, 2018)

${ }^{4}$ Foi a estratégia encontrada pelo Banco Mundial de colocar o ensino superior como ensino terciário para que houvesse a diversificação das instituições de ensino superior e dos cursos e das fontes de financiamento, ou seja, que qualquer curso após o ensino médio, com exceção do técnicos, fossem considerados de nível terciário como por exemplo os tecnológicos com duração reduzida (3 anos) como pontuado por Lima (2011).

5 Tradução nossa do seguinte texto "incrementen la diversificación institucional (aumento del número de instituciones no universitarias y privadas) para ampliar la cobertura sobre una base financiera viable y para establecer un marco de formación continua con múltiples puntos de acceso y gran variedad de itinerarios formativos"

${ }^{6}$ Grifos nossos. 
e África subsaariana, essa tendência foi intensificada pelo rápido crescimento no número e tamanho das instituições privadas de educação terciária (Banco Mundial, 2002, p. 69) ${ }^{7}$.

Podemos observar essas estratégias e seus reflexos no Brasil com a reformulação do ensino superior, com os programas de ampliação/expansão, como já supramencionado, a oferta de cursos tecnólogos (com duração de até 3 anos) considerados de nível superior e espalhados, principalmente, em instituições privadas do país. Um espaço de oferta da mercadoria/educação com custos reduzidos para o capital, inclusive no processo de formação sem o compromisso com uma concepção crítica e que de fato produza conhecimento.

Em conjunto às orientações anteriores, em 2017 foi lançado o documento/relatório elaborado pelo Grupo Banco Mundial com recomendações para o Brasil sair da crise. Intitulado "Um Ajuste Justo: Análise da eficiência e equidade do gasto público no Brasil", o documento em tela destaca várias políticas de reajuste com ênfase na política educacional em todos os níveis de ensino. Explicita também a necessidade de redução do déficit fiscal e, ao mesmo tempo, consolidar os ganhos sociais alcançados nas décadas anteriores. Neste relatório o $\mathrm{BM}$ cita a dualidade da política educacional que privilegia somente os ricos, ao negar o acesso à universidade pública aos mais pobres, tendo em vista que os exames de seleção são muito concorridos e beneficiam os estudantes com maior poder aquisitivo. Para inibir estes "privilégios" 8 compete ao governo promover mudanças na forma de acesso para permitir a todos, indistintamente, a inserção no ensino superior. Nesse relatório está bem delimitado a defesa da privatização das universidades públicas como princípio de igualar pobres e ricos no ingresso ao ensino superior (Banco Mundial, 2017, p.136).

O documento indica ainda duas linhas de reformas para o Ensino Superior: a primeira visa limitar os gastos por aluno. Para sanar a ausência de recursos repassados pelo governo federal, as universidades federais precisam procurar outras fontes de financiamento. A

\footnotetext{
7 Tradução nossa do seguinte texto: "En los pasados dos decenios, muchos países han experimentado una extraordinaria diversificación em sus sectores de educación terciaria. La aparición de diversas instituciones nuevas paralelas a las universidades tradicionales - 'institutos técnicos para estudios de corta duración, community colleges, politécnicos, centros de educación terciaria popular con programas bienales, centros de enseñanza a distancia y universidades abiertas' - ha creado nuevas oportunidades para satisfacer la demanda social creciente. En América Latina, Asia y, más recientemente, en Europa Oriental y África subsahariana, esta tendencia se ha visto intensificada por el 'rápido crecimiento en el número y tamaño de las instituciones privadas de educación terciária” (Banco Mundial, 2002, p. 69).

${ }^{8}$ Grifos nossos.
} 
sugestão é a formação de convênios com empresas privadas para que estas disponibilizem recursos de forma mais incisiva, desenvolvendo pesquisas e projetos de interesses próprios. Ao defender essa forma de financiamento o BM sinaliza para a privatização gradual das universidades públicas e permite uma diferenciação entre os cursos e seus investimentos em pesquisas e projetos de extensão, gera uma dualidade interna com cursos com maiores investimentos e outros empobrecidos por falta de recursos.

O segundo ponto seria a introdução de tarifas universitárias, nas quais utilizaria como modelo de empréstimo o FIES e, como meio de seleção, o PROUNI. Ou seja, transformar a universidade federal pública e gratuita em uma instituição híbrida, configurando-se como público/privada, pois receberia recursos do capital para serem geridas por servidores públicos.

Porém, contrário aos dados apresentados pelo BM, a Associação Nacional dos Dirigentes de Instituições Federais de Ensino Superior (Andifes) em parceria com o Fórum Nacional de Pró-reitores de Assuntos Comunitários e Estudantis (Fonaprace) publicou, em 2016, pesquisa sobre o perfil dos estudantes das Instituições Federais de Ensino Superior (IFES). A pesquisa demonstrou que $66 \%$ dos discentes das universidades públicas são oriundos de famílias com renda mensal de 1, 5 salário mínimo. Ou seja, renda familiar aquém daquela sugerida pelo BM, contrariando o pressuposto de que as instituições federais são redutos de estudantes com alto poder aquisitivo. Portanto, os dados comprovam que o relatório do BM não se vale de nenhum levantamento estatístico, mas apenas de afirmações baseadas em dados falsos para justificar cortes e ao mesmo tempo privatizar a educação superior no Brasil.

A pesquisa demonstra ainda que o pagamento de cotas por renda nas universidades públicas não é fator de inclusão dos estudantes mais pobres e, tampouco, de garantia de repasse de verbas aos outros níveis do ensino no país. Tal assertiva defendida pelo BM apenas acena na lógica afirmada por nós, qual seja: de crescente mercantilização e privatização da educação superior no Brasil. Para sustentar tais argumentos, o BM publica relatórios que sinalizam os altos custos das universidade públicas, sem levar em consideração os investimentos e o retorno que a educação superior propicia para a população onde estão inseridas as instituições de ensino superior, com pesquisas, projetos de extensão, atendimentos comunitários odontológicos, médicos, psicológicos, assistenciais, jurídicos etc. O fragmento abaixo retirado do relatório do BM explicita a concepção da referida instituição em relação aos custos da educação superior no país. 
[...] alunos nas universidades públicas brasileiras em média custam de duas a três vezes mais do que alunos matriculados em universidades privadas. Apesar desse custo por aluno bem mais elevado, em média o valor agregado das universidades públicas é semelhante ao valor agregado das universidades privadas (Banco Mundial, 2017, p.123-124).

Acrescentamos ainda que o investimento na universidade pública envolve uma grande infraestrutura, baseada em equipamentos e laboratórios, além de uma qualificação constante de seu quadro docente e técnico, fator que permite o desenvolvimento das ações supramencionadas com qualidade e de forma gratuita. "Gastos" como estes não são pontuados ao realizar tais afirmações, utilizando critérios e indicadores que mascaram a realidade de fato. Diante de tais orientações fica evidente o modo pelo qual a educação é tratada pelas lideranças do país e, principalmente, como o país é colocado no cenário internacional, como país periférico com baixo nível de desenvolvimento científico, industrial e tecnológico, com a necessidade de importação de patentes dos países centrais.

Como os governos brasileiros estão afinados com os ditames do capital internacional e financeiro, os cortes em investimento na Ciência, Tecnologia e Inovação (CT\&l) vem se dando paulatinamente, principalmente nas universidades públicas (principais centros de pesquisa do país), pelos cortes de recursos destinados aos órgãos de fomento como a Coordenação de Aperfeiçoamento de Pessoal de Nível Superior (CAPES) e do Conselho Nacional de Desenvolvimento Científico (CNPq), nas fundações estaduais como a Fundação de Amparo à Pesquisa do Estado de Minas Gerais (FAPEMIG) que anunciou o corte de mais de 5 mil bolsas de iniciação científica e a não abertura de novos editais, devido ao não repasse de $1 \%$ da arrecadação prevista na Constituição do estado de Minas Gerais (CASTRO, 2019).

Na direção dos cortes na educação, o Ministério da Educação (MEC) anunciou, em $30 / 04 / 19$, que todas as universidades federais do país sofrerão corte de $30 \%$ em seus orçamentos. A medida foi tomada após críticas recebidas pela redução de repasse de verbas às Universidade de Brasília (UNB), Universidade Federal Fluminense (UFF) e Universidade Federal da Bahia (UFBA). O corte foi justificado por Abraham Weintraub (ex-Ministro da Educação), em entrevista ao jornal Estadão, pelo fato de tais IES destinarem verbas para "fazer bagunça e evento ridículo" (AGOSTINI, 2019). O ex-ministro acrescentou ainda que toda e qualquer universidade pública que optar por este tipo de gasto, sofrerá redução no orçamento. O que não foi dito pelo ministro é que tais cortes são oriundos da necessidade de 
conter o decantado déficit fiscal para alimentar a política superavitária imposta pelo FMI e a manutenção dos pagamentos dos juros e serviços da dívida externa, que alimenta a bolha financeira e de endividamento para garantir os ganhos do capital9 ${ }^{9}$

Ou seja, a estrutura de investimentos de CT\&I no Brasil vai ao encontro das demandas e interesses do capital internacional e países centrais para os países periféricos. Reafirmam o padrão de dependência à medida que o conhecimento produzido está voltado a atender os interesses de produção de matérias primas e commodities ao invés de desenvolver tecnologias mais elaboradas para exportação de produtos manufaturados e com maior valor de mercado. Por não desenvolver tecnologia de ponta, o país importa maquinário e equipamentos de alta complexidade, assim como a compra de patentes. Essa relação impede que o país saia da situação de atraso e dependência de produtos importados. Essa política também reforça a qualificação de uma força de trabalho de baixa qualidade, ao permitir a difusão de cursos aligeirados e com pouco potencial de romper com a perspectiva tecnicista e mercadológica.

Esse movimento de destruição da CT\&I consolida nossa posição na divisão internacional do trabalho. Enquanto os países do centro possuem opções ampliadas de investimentos em várias áreas estratégicas, os países periféricos investem pouco, permitindo a dominação e controle mundial do centro sobre a periferia, caso do Brasil. Outro fator destacado por Chesnais (2005) é referente à fuga de cérebros dos países periféricos e até mesmo de países centrais em benefício dos Estados Unidos, é apontado que esta fuga é paralela e sem dúvida de uma gravidade ainda superior a fuga de capitais. Um fato complementar é que "o financiamento público é uma das principais fontes das pesquisas que promovem os Startups. É sobre o dinheiro dos contribuintes e sobre o empréstimo público que o capital de risco, tão vangloriado, se apoia" (CHESNAIS, 2005, p.56).

Neste sentido, podemos afirmar que nosso país caminha a passos rápidos para uma total subordinação ao capital internacional financeiro e predatório. Nossa posição na divisão internacional do trabalho, defendida por uma burguesia nacional míope e mesquinha, reforça os altos índices de desigualdade social, de concentração de renda e de quadros de miserabilidade da população, além das taxas elevadas de desemprego, informalidade e

\footnotetext{
${ }^{9}$ Exemplo paradigmático é a PEC do teto de gastos (inicialmente PEC 241, depois PEC 55, atualmente EC 95), aprovada no governo de Michel Temer e que estabelece redução dos investimentos na área da saúde e da educação.
} 
precariedade das relações trabalhistas. Notamos que não é considerado sequer mudanças na estrutura da formação sócio histórica brasileira, o que implica negar uma concepção de educação inclusiva e que possibilite a formação crítica. Ou seja, o atual estágio de acumulação de capital, na sua fase imperialista e financeira, drena o capital e abocanha tudo o que é possível no Brasil para alimentar a fome voraz dos mandatários do poder econômico e financeiro, representado aqui por uma política nacional em total conivência com as diretrizes do BM e do FMI.

\section{Considerações finais}

A partir da leitura dos relatórios é possível considerar que as proposições do BM vêm se consolidando, e, merece destaque o fato de que grande parte dos relatórios sugerem a cobrança de taxas com uma nítida perspectiva de mercantilização da educação. Porém, quando os dados da realidade são analisados de maneira ampla é evidenciado que este sistema de financeirização da educação através de bolsas/empréstimos bancários é insustentável a longo prazo, tanto no Brasil, quanto nos países tidos como centrais/desenvolvidos. Os índices de inadimplência e de endividamento é evidência desta dinâmica, em que os principais beneficiados são apenas o capital financeiro e especulativo.

Isto porque o desemprego é uma realidade que atinge a todos indistintamente. $\mathrm{O}$ mito da qualificação ou formação para o mercado de trabalho não se sustenta, pois não há vagas para todos. Nessa lógica da formação e qualificação para o mercado de trabalho o que ocorre é a maior mercantilização da educação e a responsabilidade pela não inserção do trabalhador no mercado como algo exclusivo e individual do sujeito que vivencia tal condição. O que também é funcional ao modo de produção capitalista, pois cria a ideia de mérito, capacidades individuais, competição entre os próprios trabalhadores e aceitação de todo e qualquer tipo de emprego.

Por outro lado, a qualificação proposta é tecnicista e adequada aos interesses da extração da mais valia absoluta e relativa, ao produzir e reproduzir uma formação asséptica e acrítica para perpetuar ideologicamente a dominação de classe. O Estado brasileiro, por sua vez, está comprometido com os ditames dessa política predatória em que a permanência da subalternidade, da dependência, da desigualdade e da inserção periférica na divisão internacional do trabalho não se rompe. Pelo contrário, o país mantém-se como país 
agroexportador e submisso ao capital internacional com uma burguesia tacanha que prefere vender-se por migalhas ao senhor mercado em detrimento de uma proposta de ruptura com o atraso.

\section{Referencial Bibliográfico}

ANDIFES; FONAPRACE. IV Pesquisa do perfil socioeconômico e cultural dos estudantes de graduação das instituições federais de ensino superior brasileiras em 2014. Universidade Federal de Uberlândia (UFU): Uberlândia, julho de 2016. Disponível em:

<http://www.andifes.org.br/wp-content/uploads/2017/11/Pesquisa-de-Perfil-dosGraduanso-das-IFES 2014.pdf> Acesso em: 15 abr. 2018.

BANCO MUNDIAL. El financiamiento de la educación en los países en desarrollo: opciones de política. Washington, 1986. Disponível em:

http://documentos.bancomundial.org/curated/es/614071468163754682/El-financiamientode-la-educacion-en-los-paises-en-desarrollo-opciones-de-politica> Acesso em: 20 ago. 2018.

BANCO MUNDIAL. Prioridades y estratégias para la educación: examen del Banco Mundial. Washington, 1996. Disponível em:

http://documents1.worldbank.org/curated/pt/715681468329483128/pdf/14948010spanish. $\underline{\mathrm{pdf}}>$ Acesso em: 18 jul. 2018.

BANCO MUNDIAL. Como procurar las capacidades necesarias para la economia del conocimiento: el Banco Mundial en la educación terciaria de América Latina y el Caribe. Washington, 2002. Disponível em:

<http://documents.worldbank.org/curated/pt/164861468774286476/Como-procurar-lascapacidades-necesarias-para-la-economia-del-conocimiento-el-Banco-Mundial-en-laeducacion-terciaria-de-America-Latina-y-el-Caribe> Acesso em: 11 set. 2018.

BANCO MUNDIAL. Um Ajuste Justo: Análise da eficiência e equidade do gasto público no Brasil. Revisão Das Despesas Públicas. Volume I: Síntese. Washington, 2017. Disponível em: <http://www.worldbank.org/pt/country/brazil/publication/brazil-expenditure-reviewreport> Acesso em: 05 de mar. 2018.

BRASIL. MEC. Estudantes inadimplentes poderão renegociar as dívidas com o Fies a partir do segundo semestre. Brasília: 2018. Disponível em: http://portal.mec.gov.br/ultimasnoticias/213-1762821894/65601-estudantes-inadimplentes-poderao-renegociar-as-dividascom-o-fies-a-partir-do-segundo-semestre > Acesso em: 11 nov. 2018.

CASTRO, F. Em crise, Fapemig corta 5 mil bolsas de iniciação científica e novos editais. Jornal online Direto da ciência, 2019. Disponível em:

<http://www.diretodaciencia.com/2019/03/01/em-crise-fapemig-corta-5-mil-bolsas-deiniciacao-cientifica-e-novos-editais/> Acesso em 08 mar. 2019. 
CHESNAIS, F.. A mundialização do capital. São Paulo: Xamã, 1996.

CHESNAIS, F. O neoliberalismo sob a hegemonia norte americana. In: CHESNAIS, François (Org.). A finança mundializada: raízes sociais e políticas, configuração, consequências. São Paulo: Boitempo, 2005. p. 85- 108.

FERREIRA, A. T. S.; PEREIRA, L. D.; SOUZA, A. C. V.. Ensino superior mercantilizado e seus impactos para o perfil profissional de Serviço Social. In: Educação e Serviço Social: Subsídios para uma análise crítica. Rio de Janeiro: Lumen Juris, 2017. p.187-209.

LIMA, K. R. S. O Banco Mundial e a educação superior brasileira na primeira década do novo século. Revista Katálysis, Florianópolis, v. 14, n. 1, p. 86-94, jan./jun. 2011.

MARTINS, J.R. Immanuel Wallerstein e o sistema-mundo: uma teoria ainda atual? Iberoamérica Social: Revista-Red de Estudios Sociales (V), p. 95-108. 2015. Disponível em: <http://iberoamericasocial.com/immanuel-wallerstein-e-o-sistema-mundo-uma-teoriaainda-atual/> Acesso em: 10 fev. 2018.

MARX, K. Crítica do Programa de Gotha. Tradução Rubens Enderle. São Paulo: Boitempo, 2012.

MELO, A. A. S.. A mundialização da educação: neoliberalismo e social-democracia no Brasil e na Venezuela. Revista Trabalho, educação e saúde [online], vol.3, n.2, p.397-408.

2005.Disponível em: <http://www.scielo.br/scielo.php?script=sci_arttext\&pid=S1981-

$77462005000200008>$ Acesso em: 19 jul. 2018.

NETTO, J. P.. Ditadura e serviço social: uma análise do serviço social no Brasil pós-64. 8 ed. São Paulo: Cortez, 2005. p.13-112.

NEVES, L. M. W. As reformas da educação escolar brasileira e a formação de um intelectual urbano de novo tipo. In: Anais da 27ạ Reunião Anual da ANPED, 2004, Caxambu: ANPED, 2004. Disponível em: <http://www.anped.org.br/sites/default/files/t0510.pdf> Acesso em: 7 mar. 2019.

OLIVEIRA, C. M. As Influências do Banco Mundial na Política educacional: o foco na educação e na regulação social. Reunião científica regional da ANPED: Educação, movimentos sociais e políticas governamentais. UFPR: Curitiba/PR. 2016. ISBN: 978-85-8465013-2. Disponível em: <http://www.anpedsul2016.ufpr.br/portal/wpcontent/uploads/2015/11/eixo4_CAROLINE-MARI-DE-OLIVEIRA.pdf> Acesso em: 28 mar. 2018.

TOMÁZ, Jéssica Adrielle Pereira. Uma análise dos relatórios do Banco Mundial e a mercantilização da educação nos países periféricos em particular o Brasil. Dissertação (Mestrado). Universidade Federal de Juiz de Fora, Faculdade de Serviço Social, 2019. 